\title{
Crack Initiation in Asphalt Mixtures under External Compressive Loads
}

\author{
Yuqing Zhang ${ }^{\mathrm{a}, *}$, Xue Luo ${ }^{\mathrm{a}}$, Rong Luo ${ }^{\mathrm{a}}$, Robert L. Lytton ${ }^{\mathrm{b}}$ \\ a Texas A\&M Transportation Institute, College Station, TX, USA \\ Postal address: CE/TTI Bldg 508E, 3135 TAMU, College Station, Texas 77843-3135 \\ ${ }^{\mathrm{b}}$ Zachry Department of Civil Engineering, Texas A\&M University, College Station, TX, USA \\ Postal address: CE/TTI Bldg 503A, 3136 TAMU, College Station, Texas 77843-3136 \\ *Corresponding author. Tel.: 1-979-739-5366. Fax: 1-979-845-0278 \\ Emails addresses: \\ zyqtamu@tamu.edu (Yuqing Zhang) \\ xueluo@tamu.edu (Xue Luo) \\ rongluo@ tamu.edu (Rong Luo) \\ r-lytton@ civil.tamu.edu (Robert L. Lytton)
}

\begin{abstract}
Crack initiation was studied for asphalt mixtures under external compressive loads. High tensile localized stresses near the edges of compressed air voids lead to the growth of wing cracks in the direction of the external loads. A quantitative crack initiation criterion was derived using pseudostrain energy balance principle. Bond energy is determined and it increases with aging and loading rate while decreases with temperature. Cohesive and adhesive cracking occur simultaneously and a method was proposed to determine the individual percentage. The crack initiation criterion is simplified and validated through comparing the predicted and measured compressive strength of the asphalt mixtures.

Key words: Asphalt mixtures; Crack initiation; Compressive loads; Pseudostrain energy; Bond energy; Compressive strength
\end{abstract}

\footnotetext{
${ }^{1}$ This is an Accepted Manuscript of an article published by Elsevier in Construction and Building Materials. The final publication is available online via http://dx.doi.org/10.1016/j.conbuildmat.2014.09.009
} 


\section{Introduction}

Constitutive modeling of an asphalt mixture under an external compressive load requires different theories at different stages of the material. Viscoelastic theories are normally used to characterize nondestructive material behaviors and predict recoverable deformation. A yield criterion defines when the asphalt mixture begins yielding and from which irrecoverable viscoplastic deformation is initially accumulated. A hardening rule specifies the successive yielding after the initial yielding. For asphalt mixtures, it follows a strain/work hardening flow rule. The viscoplastic deformation will approach an asymptote and become saturated if no damage is introduced into the material. With the occurrence of damage the constitutive relation of the asphalt mixture exhibits strain-softening, a phenomenon that stress declines as strain increases. The peak stress is compressive strength. To characterize this overstress behavior of asphalt mixtures, a damage parameter is normally utilized in the stress-strain relationship and an evolution equation needs to be provided for this damage parameter. Three questions are raised by the authors that include 1) what the damage is physically; 2) when the damage initially occurs; and 3) what fundamental mechanisms the damage follows during its evolution. The authors focus on clarifying the first two questions in this study and will address the third question in a future study.

Two theories are currently used by the pavement research community to model the damaged behavior of asphalt mixtures: viscoelastic continuum damage (VECD) theory and continuum damage mechanics (CDM) model. The VECD theory was originally developed by Schapery [1-3], in which an internal state variable (i.e., $S$ ) was used as a representative of the damage in viscoelastic materials. An extended elastic-viscoelastic correspondence principle was proposed and the stress was linearly related to pseudostrain (i.e., $\varepsilon^{R}$ ) by a normalized pseudostiffness (i.e., $C(S)$ ) for the viscoelastic materials with damage. The evolution of the damage parameter was formulated as a power function of the pseudostrain energy (PSE) density. Schapery's viscoelastic damage theory was applied extensively in modeling the constitutive behavior of asphalt mixtures at low and moderate temperatures and in tension [4-9]. The timedependent damage was interpreted as the growth of microcracks in tension. Gibson [10] and Schwartz et al. [11] extended these theories to characterize the viscoelasticity and damage of the asphalt concrete under compressive loadings, in which Schapery's viscoplastic models [3, 12] were introduced to account for the viscoplastic deformation of the asphalt mixtures in compression. Then the total deformation was the sum of the damaged viscoelastic deformation and the viscoplastic deformation. The extended VECD theory that includes viscoplasticity is called viscoelastic plastic continuum damage (VEPCD) method, summary of which can be found in a project report [13]. In general, the VECD (or VEPCD) method characterizes the damage as a degradation of the normalized pseudo-stiffness and does well at low and moderate temperatures and in tension. However, more efforts are needed to explicitly specify the fundamental damage mechanisms of the asphalt mixtures. It is not clear that, especially in compression and at relatively high temperatures, how the damages are initiated and how the damage departs from the viscoplastic deformation.

The CDM model interprets the damage as a reduction of the intact material area due to cracks, voids and flaws existing in the material $[14,15]$. The characteristic parameter is damage density that is the ratio of the lost area to the total apparent area of the material, as below [16]:

$$
\xi=\frac{A_{L}}{A_{0}}=1-\frac{\sigma^{A}}{\sigma^{T}}
$$


where $\xi$ is the damage density, $A_{L}$ is the lost area and $A_{0}$ is the total (apparent) area of a cross section. $\sigma^{A}$ is the apparent stress acting on the total material area and $\sigma^{T}$ is the effective (or true) stress acting on the intact material area $\left(A_{0}-A_{L}\right)$. Effective stress is used in the constitutive relations to account for the influences of the damage. For example, the damage density and the effective stresses were embedded in Perzyna's rate-dependent viscoplastic theories [17] and used to characterize the viscoplasticity and viscodamage of asphalt mixtures [18-21]. These studies provided a comprehensive damage characterization for asphalt mixtures and indicated that the damage was due to the loss of the intact material area. The viscodamage thermodynamic driving force was developed to have a similar formulation to the extended Druker-Prager yield surface model. The evolution models for the viscoplasticity and the viscodamage were both formulated as power functions of the corresponding driving forces [22, 23]. However, it is not clear how the viscodamage differs from the viscoplasticity. Furthermore, considerable laboratory efforts are needed to determine the parameters for the viscoplastic and viscodamage models. More studies are also needed to explain fundamentally what the damage exactly is, when the damage is initiated and how the damage evolves and differs from the viscoplasticity, especially in compressive loading conditions.

The two theories above both indicate that the damages in asphalt mixtures are microcracks in addition to viscoplastic deformation. Some studies in the literature have also directly demonstrated that, when subject to external compressive loads, cracks are initiated and propagated in the asphalt mixtures and lead to the cracking damage when the viscoplastic deformation approaches the saturation. Cracks were experimentally observed in compressive tests [24] and micro-cracking was modeled as one of the components of rutting [25]. Lytton [26] emphasized that the tertiary creep of rutting is not a plastic flow but a growth of microcracks. Both Wang et al. [27] and Freitas et al. [28] reported that cracks were observed within the compressive stress zone in the wheel-tracking rutting tests on asphalt mixtures at relatively high temperatures and they interpreted this phenomenon as one of the reasons for top-down cracking. Underwood et al. [29] explained that, in compression, the damages were the microcracks that developed in a direction parallel to the loading direction and found that this microcrack-induced damage may be significant for conditions when rutting is a primary concern. The authors' studies $[30,31]$ demonstrated that the tertiary flow of rutting was caused principally by the growth of microcracks, which is parallel to the direction of the external loads and signaled by the increase of the phase angle in the tertiary stage. The tertiary flow under repeated compressive loading was characterized by an anisotropic viscofracture theory based on the damage density and Pseudo Jintegral Paris' law [32].

The objective of this paper is to develop a microcrack (i.e. damage) initiation criterion for asphalt mixtures in compression based on fracture mechanics. At the peak stress (i.e., compressive strength) of a monotonic compressive load test or at the flow number of a repeated compressive load test, the asphalt mixtures are sufficiently hardened by viscoplastic work that no more energy due to external loads can be dissipated for viscoplastic deformation which has become saturated. The extra energy must be consumed for the initiation of the microcracks. Thus the microcracks are believed to be initiated at the compressive strength under monotonic load or at the flow number under repeated load. This initiation is demonstrated by the increased phase angle in the tertiary stage $[30,32]$. The next section shows the materials and laboratory tests used in this study, which is followed by viscoelastic characterization based on the pseudostrain concept. Then, a quantitative criterion for crack initiation is proposed for asphalt mixtures under external compressive loads based on fracture mechanics. Subsequently, the crack initiation criterion is employed to analyze the test results and determine the bond energy of the asphalt mixtures, which are decomposed into cohesive bond energy and adhesive bond energy. The 
crack initiation criterion is also simplified based on test results and validated through the compressive strength test data obtained in the literature for different types of asphalt mixtures at different conditions.

\section{Materials and Laboratory Tests}

Table 1 summarizes the test materials, test protocols and loading parameters of the laboratory tests used in this study. Twenty types of asphalt mixtures were tested with four binders, two air void contents (e.g., 4\% and 7\%) and three aging periods (i.e., unaged, 3-month and 6 month continuously aged at $60^{\circ} \mathrm{C}$ in a conditioning room). The AAD-1 and AAM-1 binders were from Strategic Highway Research Program (SHRP) materials reference library [33] and the NuStar and Valero binders were from Asphalt Research Consortium (ARC) project. Uniaxial compressive creep (UCC) tests were performed to determine the viscoelastic properties of the mixtures such as creep compliance and relaxation modulus. The UCC test temperature was $40^{\circ} \mathrm{C}$ and a constant stress of $40 \mathrm{kPa}$ was used. Uniaxial compressive strength (UCS) tests were conducted on each type of the mixtures with at least two replicates and a third replicate was tested if a high variation was found in the results. The UCS test temperature was $40^{\circ} \mathrm{C}$ and the strain rate was $311 \mu \varepsilon / \mathrm{sec}$. To evaluate the effects of temperature and strain rate, one type of asphalt mixture samples (NuStar binder, 4\%, 6-month aged) were tested at five different temperatures using the UCC and UCS tests, as shown in Table 1. Another type of asphalt mixture samples (NuStar binder, 7\%, 6-month aged) were tested at five different strain rate levels using the UCS tests, as shown in Table 1.

For all asphalt mixtures, a common Texas limestone was used and the aggregate gradation was determined from a Type $\mathrm{C}$ dense gradation, specified by Texas Department of Transportation (TxDOT) [34]. The optimum asphalt content was calculated based on the TxDOT test procedure at the target air void content [35]. All of the tests were conducted on cylindrical asphalt mixture specimens with a diameter of $100 \mathrm{~mm}$ and a height of $150 \mathrm{~mm}$. The Universal Testing Machine (UTM) was utilized to perform the tests. The stress was controlled at a constant in the UCC tests and the strain rate was controlled at a constant in the UCS tests. The loading parameters are shown in Table 1. Three linear variable differential transformers (LVDTs) were glued to the lateral surface of the samples and used to record the axial deformation under compressive loads.

Table 1

Laboratory Test Materials, Protocols and Parameters for Asphalt Mixtures.

\begin{tabular}{|c|c|c|c|c|}
\hline Binder & $\begin{array}{c}\text { Air Void } \\
\text { Content }(\%)\end{array}$ & $\begin{array}{l}\text { Aging Period } \\
\text { (Month) }\end{array}$ & Asphalt Mixture Label & Test Methods \\
\hline \multirow{4}{*}{$\begin{array}{c}\text { AAD-1 } \\
\text { (PG58-28) }\end{array}$} & \multirow{2}{*}{4} & 0 & AAD 4\% 0 mon* & \multirow{11}{*}{$\begin{array}{l}\text { (2) Uniaxial Compressive } \\
\text { Strength (UCS) Tests }\end{array}$} \\
\hline & & 6 & AAD 4\% 6 mon & \\
\hline & \multirow{2}{*}{7} & 0 & AAD 7\% 0 mon & \\
\hline & & 6 & AAD 7\% 6 mon & \\
\hline \multirow{4}{*}{$\begin{array}{c}\text { AAM-1 } \\
(\text { PG64-16) }\end{array}$} & \multirow{2}{*}{4} & 0 & AAM 4\% 0 mon & \\
\hline & & 6 & AAM $4 \% 6$ mon & \\
\hline & \multirow{2}{*}{7} & 0 & AAM $7 \% 0$ mon & \\
\hline & & 6 & AAD 7\% 6 mon & \\
\hline \multirow{3}{*}{$\begin{array}{c}\text { NuStar } \\
\text { (PG67-22) }\end{array}$} & \multirow{3}{*}{4} & 0 & NuS 4\% 0 mon & \\
\hline & & 3 & $\mathrm{NuS} 4 \% 3$ mon & \\
\hline & & 6 & $\mathrm{NuS} 4 \% 6$ mon & \\
\hline
\end{tabular}




\begin{tabular}{|c|c|c|c|c|}
\hline & \multirow{3}{*}{7} & 0 & $\mathrm{NuS} 7 \% 0 \mathrm{mon}$ & \\
\hline & & 3 & $\mathrm{NuS} 7 \% 3 \mathrm{mon}$ & \\
\hline & & 6 & $\mathrm{NuS} 7 \% 6$ mon & \\
\hline \multirow{6}{*}{$\begin{array}{c}\text { Valero } \\
\text { (PG64-16) }\end{array}$} & \multirow{3}{*}{4} & 0 & VaL 4\% 0 mon & \\
\hline & & 3 & VaL 4\% 3 mon & \\
\hline & & 6 & VaL 4\% 6 mon & \\
\hline & \multirow{3}{*}{7} & 0 & VaL 7\% 0 mon & \\
\hline & & 3 & VaL 7\% 3 mon & \\
\hline & & 6 & VaL $7 \% 6$ mon & \\
\hline \multirow{5}{*}{$\begin{array}{c}\text { NuStar } \\
\text { (PG67-22) }\end{array}$} & \multirow{5}{*}{4} & \multirow{5}{*}{6} & $\mathrm{NuS} 4 \% 6$ mon $\left[40^{\circ} \mathrm{C}\right]$ & $\mathrm{UCC}$ and UCS at $40^{\circ} \mathrm{C}$ \\
\hline & & & $\mathrm{NuS} 4 \% 6$ mon $\left[45^{\circ} \mathrm{C}\right]$ & $\mathrm{UCC}$ and $\mathrm{UCS}$ at $45^{\circ} \mathrm{C}$ \\
\hline & & & $\mathrm{NuS} 4 \% 6$ mon $\left[50^{\circ} \mathrm{C}\right]$ & $\mathrm{UCC}$ and UCS at $50^{\circ} \mathrm{C}$ \\
\hline & & & $\mathrm{NuS} 4 \% 6$ mon $\left[55^{\circ} \mathrm{C}\right]$ & $\mathrm{UCC}$ and $\mathrm{UCS}$ at $55^{\circ} \mathrm{C}$ \\
\hline & & & $\mathrm{NuS} 4 \% 6$ mon $\left[60^{\circ} \mathrm{C}\right]$ & $\mathrm{UCC}$ and UCS at $60^{\circ} \mathrm{C}$ \\
\hline \multirow{5}{*}{$\begin{array}{c}\text { NuStar } \\
(\text { PG67-22) }\end{array}$} & \multirow{5}{*}{7} & \multirow{5}{*}{6} & $\mathrm{NuS} 7 \% 6$ mon $[18 \mu \varepsilon / \mathrm{sec}]$ & $\mathrm{UCS}\left(40^{\circ} \mathrm{C}, 18 \mu \varepsilon / \mathrm{sec}\right)$ \\
\hline & & & $\mathrm{NuS} 7 \% 6$ mon $[65 \mu \varepsilon / \mathrm{sec}]$ & $\mathrm{UCS}\left(40^{\circ} \mathrm{C}, 65 \mu \varepsilon / \mathrm{sec}\right)$ \\
\hline & & & $\mathrm{NuS} 7 \% 6$ mon $[311 \mu \varepsilon / \mathrm{sec}]$ & $\mathrm{UCS}\left(40^{\circ} \mathrm{C}, 311 \mu \varepsilon / \mathrm{sec}\right)$ \\
\hline & & & $\mathrm{NuS} 7 \% 6$ mon $[622 \mu \varepsilon / \mathrm{sec}]$ & $\mathrm{UCS}\left(40^{\circ} \mathrm{C}, 622 \mu \varepsilon / \mathrm{sec}\right)$ \\
\hline & & & $\mathrm{NuS} 7 \% 6$ mon $[1074 \mu \varepsilon / \mathrm{sec}]$ & $\mathrm{UCS}\left(40^{\circ} \mathrm{C}, 1074 \mu \varepsilon / \mathrm{sec}\right)$ \\
\hline
\end{tabular}

\section{Viscoelastic Properties of Asphalt Mixtures}

The viscoelastic properties of asphalt mixtures are characterized by relaxation modulus (i.e., $E(t)$ ). It can be determined by performing Laplace transformations on creep compliance that is measured from the UCC tests. Then the relaxation modulus is represented by a Prony series model. Details of determining the relaxation modulus and the coefficients of the Prony series model can be found in the previous studies $[31,36]$.

Pseudostrain was proposed in the elastic-viscoelastic correspondence principle by Schapery [1] as below:

$$
\varepsilon^{R}(t)=\frac{1}{E_{R}} \int_{0^{-}}^{t} E(t-s) \frac{d \varepsilon(s)}{d s} d s
$$

where $\varepsilon^{R}$ is the pseudostrain. $\varepsilon(s)$ is the measured total strain. $s$ is the time before current time $t$. $E(t)$ is the relaxation modulus. $E_{R}$ is a reference modulus. Pseudostrain was proved to be capable of removing the viscous effect on the responses of a viscoelastic material and had been used in the damage characterization of asphalt mixtures [4, 5, 37]. The authors proved that, if Young's modulus is assigned as the reference modulus, pseudostrain has a physical meaning that is the difference between total strain and the viscous strain [31]. As a result, the total strain was decomposed to elastic strain, viscous strain, plastic strain, viscoplastic strain and viscofracture strain under monotonic loads and repeated loads, respectively [31, 36]. It was also demonstrated that, the viscoelasticity, viscoplasticity and viscofracture can be efficiently differentiated and individually modeled by different mechanisms [30, 32].

Figure 1 shows the stress-pseudostrain curve for a uniaxial compressive strength test. A linear relation is found between stress and pseudostrain before the initial yield strength. After this point, strain hardening is characterized using the data between the initial yield strength and the ultimate yield strength. Thus, using stress-pseudostrain relation, the asphalt mixture can be characterized as an elastic-viscoplastic material before the ultimate yield strength (i.e., compressive strength). Then, microcracks are initiated at the moment of the compressive strength. 
The decline of the stress-pseudostrain curve after the compressive strength is hypothesized to be caused by the propagation of the microcracks, which leads to the degradation of the material apparent stiffness and will be characterized using fracture methods in a future study. This study is focused on the crack initiation at the moment of the compressive strength.

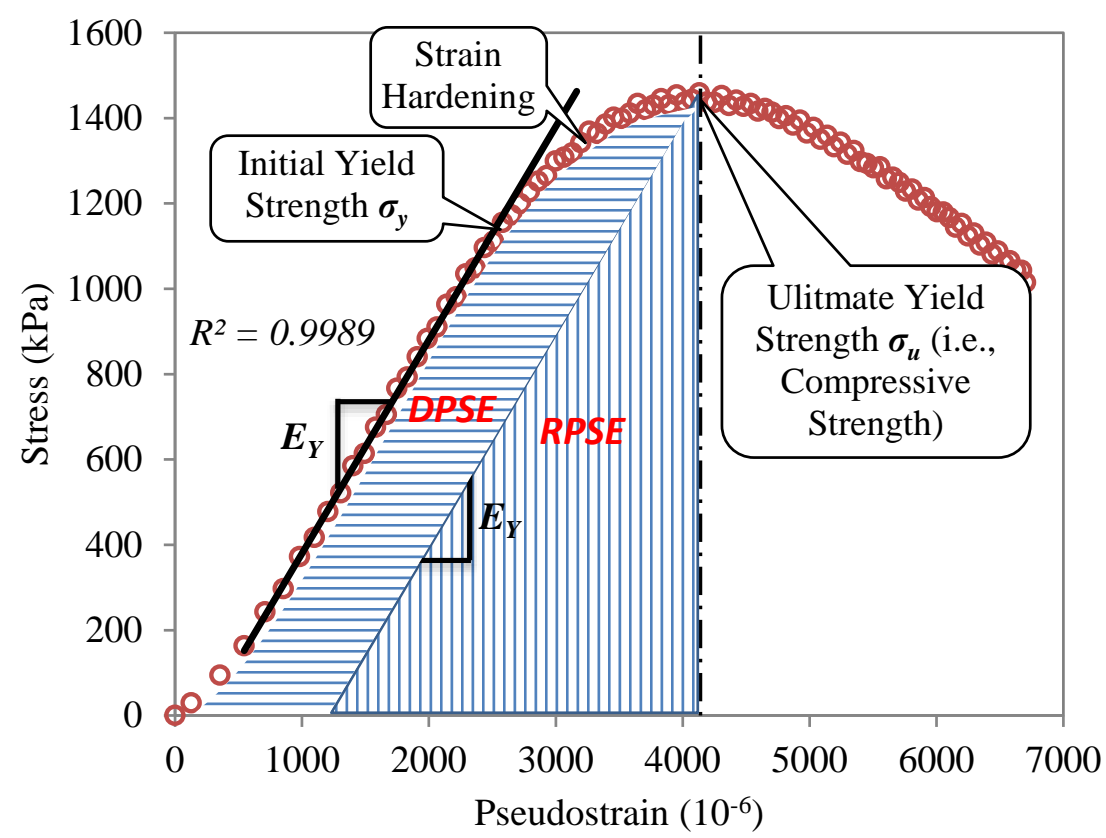

Fig. 1. Stress-pseudostrain curve of an asphalt concrete and calculations of dissipated pseudostrain energy (DPSE) and recoverable pseudostrain energy (RPSE).

As shown in Figure 1, the area below the stress-pseudostrain curve is the pseudostrain energy (PSE) which includes dissipated pseudostrain energy (DPSE) and recoverable pseudostrain energy (RPSE). DPSE is the energy dissipated for the development of viscoplastic deformation and is shown by the horizontally shaded area in Figure 1. RPSE is the energy stored in the intact material and can be released and recovered during unloading, which is shown as the vertically shaded triangular area in Figure 1. It is worth noting that the unloading of the stresspseudostrain curve is hypothesized to have the identical slope as the loading process and both are the Young's modulus. The logic of this hypothesis is that the pseudostrain removes the viscous effect on the material responses and the remaining behavior during the pseudostrain unloading is an elastic response. Nevertheless, on-going studies using laboratory loading-unloading tests are being performed to validate this hypothesis.

\section{Crack Initiation Analysis based on Energy Redistribution}

\subsection{Crack Initiation of Civil Materials in Compression}

The cracking mode of an asphalt mixture in compression differs significantly from that in tension. It is known that, when subjected an external tensile load, the cracks tend to grow in a direction that is perpendicular to the direction of the tensile stress. However, in compression, the cracks are prone to propagate in the direction that is parallel to the direction of the external compressive loads. Based on the authors' study [32], the primary direction of the compressive cracks that dominates the rupture of the asphalt concrete in compression can be either splitting cracks or diagonal cracks depending on the stiffness and initial air void contents of the asphalt concrete mixtures. In general, a softer asphalt mixture that has a larger air void content tends to 
have a diagonal cracking in compression, whereas a stiffer asphalt mixture having a smaller air void content tends to have a splitting cracking in compression.

Few efforts have been focused on the crack initiation of asphalt mixtures under an external compressive load. However, many important findings regarding the crack initiation in compression were reported for some other civil materials such as glass, casting resin, cement, mortar and rocks when subjected to external compressive loads. These findings are reviewed as follows and serve as a basis of understanding the crack initiation in civil materials under the external compressive load.

Hoek and Bieniawski [38] found that, for a rock under uniaxial compression, crack initiation commenced with the sudden appearance of small cracks (i.e., wing cracks) of approximately 0.2 times of the length of the pre-existing crack. The wing cracks followed a curved path and ceased when the crack path became parallel to the major principal stress direction. Germanovich et al. [39] concluded that isolated three-dimensional (3-D) cracks cannot propagate any appreciable distance and the sizes of the wing cracks were of the order of the initial crack dimensions. Large localized tensile cracks did appear near the crack tips under uniaxial compression, which may be due to the interaction of pre-existing flaws/voids/cracks. Reyes and Einstein [40] performed finite element analysis on two adjacent inclined pre-existing cracks within a rock-like material under far-field external compressive loads. Dyskin et al. [41] investigated the mechanisms of 3-D crack development in uniaxial compression for resin, cement and mortar samples. Their studies indicated that, before the growth of wing cracks, significantly high tensile stresses parallel to the pre-existing cracks are produced near the crack tips, as shown in Figure 2. The parallel tensile stresses are prone to cause the opening of wing cracks in the direction perpendicular to the pre-existing cracks. The growth of wing cracks releases the high tensile stresses near the crack tips. The materials releasing the energy for wing crack opening are in the triangular zones formed by the pre-existing cracks and the new wing cracks, which are shown as the red triangles plotted in Figure 2. They also found that high stresses are induced near the tips of the wing cracks once the wing cracks appear in the material.

The image of 3-D wing cracks was obtained using a transparent resin sample as shown in Figure 2. This study confirmed that a single 3-D internal cracks would not grow substantially to cause failure whereas the influence of interactions between multiple initial cracks always generated tensile fractures parallel to the loading direction [41]. Multi-cracks with different arrangements were tested in compression and the dimensions of the wing cracks were measured. Based on these measurements, it is statistically determined that the average width of the wing crack (as shown in Figure 2) is $b=0.6 c$ (standard deviation of $b$ is $0.291 c$ ) and the average length of the wing crack is $h=0.8 c$ (standard deviation of $h$ is $0.255 c$ ), where $c$ is the radius of the pre-existing crack which has a circular penny shape. These wing crack configurations and dimensions will be employed in the determination of energy redistribution during crack initiation in the next section. 


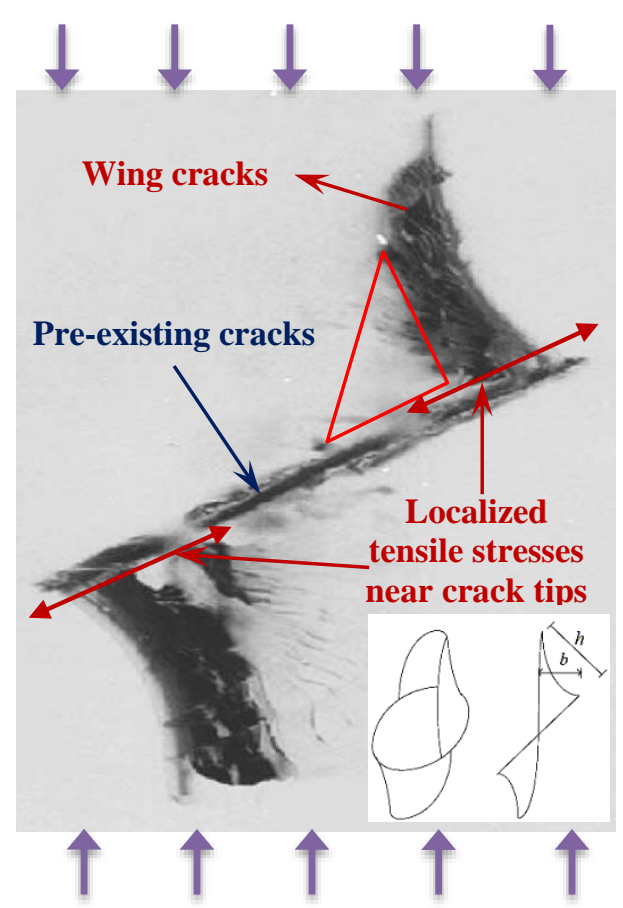

Fig. 2. Image and schematic plots of three dimensional wing cracks in a transparent resin sample induced by external compressive loads in vertical direction [41].

\subsection{Energy Redistribution due to Wing Cracks in Compression}

Crack opening is a process of energy redistribution in the material according to Griffith theory. For asphalt mixtures, the dissipated energy due to viscoelastic relaxation has been subtracted from the total strain energy. The resulting pseudostrain energy (PSE) which is based on the stress-pseudostrain relation is the energy driving the elastic, viscoplastic and viscofracture deformation. The total PSE is redistributed due to the appearance of the new wing cracks as follows: the recoverable pseudostrain energy (RPSE) is released from the intact material near the new crack wings (e.g., the triangular zones shown in Figure 2). The dissipated pseudostrain energy (DPSE) is consumed by the viscoplastic deformation accumulated in the area of the wing crack tips. In addition, surface energy is stored on the surfaces of the new wing cracks. Thus, the energy redistribution due to new wing cracks is formulated as:

$$
\mathrm{E}=P S E \cdot \mathrm{V}_{0}-R P S E \cdot 2 \mathrm{~V}_{R} \cdot m+D P S E \cdot 2 \mathrm{~V}_{D} \cdot m+\Delta G \cdot 2 \mathrm{~S}_{w} \cdot m
$$

where $\mathrm{E}$ is total pseudo energy of a representative volume element (RVE). PSE is the pseudostrain energy (density). $\mathrm{V}_{0}$ is the total volume of the RVE. RPSE is the recoverable pseudostrain energy (density). $\mathrm{V}_{\mathrm{R}}$ is the volume of the material that releases RPSE. DPSE is the dissipated pseudostrain energy (density) for viscoplastic deformation. $V_{D}$ is the material volume where viscoplastic deformation occurs. $\Delta G$ is the bond energy (or Gibbs free energy) of the asphalt mixture, which is the energy (or work) of adhesion or cohesion per unit of crack surface area created. $S_{w}$ is the surface area of a new wing crack. $m$ is the total number of pre-existing cracks in the RVE. Coefficients of 2 appearing in Equation 3 refer to two wing cracks (one upwards and one downwards) that originate from each of the pre-existing cracks or voids as shown in Figure 2. In asphalt mixtures, the air voids are the inherent flaws/voids since the asphalt concrete mixtures are fabricated by compaction and air voids are inherently embedded in the mixtures once compacted. Thus air voids are regarded as the pre-existing cracks and the new 
wing cracks are initiated from the air voids of asphalt mixtures, due to the tensile stress concentration near the edges of the air voids (cracks), as shown in Figure 2.

To determine $V_{0}, V_{R}, V_{D}$ and $S_{w}$, the pre-existing cracks are assumed to have a circular penny shape, which is a rational assumption as the air voids of the asphalt mixtures are compressed and squeezed to some extent by external compressive loads during the viscoplastic deformation accumulation. Two wing cracks grow from the edge of the pre-existing crack along the direction of the external compressive load, as shown in Figure 3.

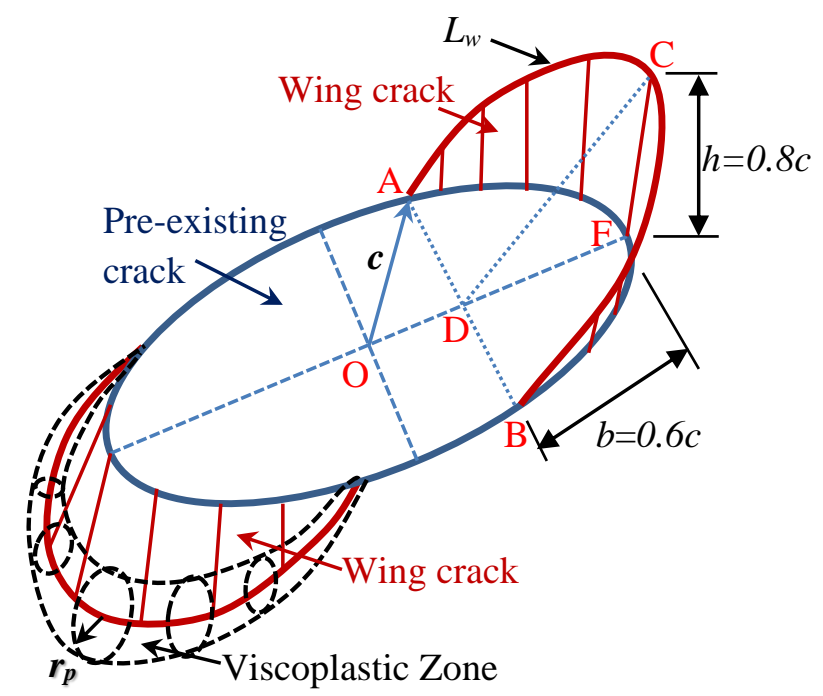

Fig. 3. Configurations of a pre-existing crack and propagated wing cracks under an external compressive load in vertical direction.

The 3-D wing cracks are shown as the two vertical shaded surfaces in red color in Figure 3. The material releasing RPSE due to the opening of wing cracks is within the volume wrapped by the wing cracks and the pre-existing crack (e.g., volume ADBFC in Figure 3). The volumes of the materials consuming DPSE for viscoplastic deformation due to wing cracks are illustrated as curved cylinders with changing radius along the outer edge of the wing cracks shown as the area formed by the dashed curves in Figure 3 (both top and bottom wing cracks have viscoplastic zones, but only the bottom one is illustrated in Figure 3). The corresponding material volumes and wing crack surface area are determined as below:

$$
\left\{\begin{array}{l}
\mathrm{V}_{0}=A t \\
\mathrm{~V}_{R}=\text { volume of } A D B F C \approx \frac{\pi}{12} c^{3} \\
\mathrm{~V}_{D}=\frac{1}{3} \pi\left(r_{p}\right)^{2} L_{w} \approx \frac{1}{3} \pi\left(\frac{h}{4}\right)^{2} 3 c \approx \frac{\pi}{24} c^{3} \\
\mathrm{~S}_{w}=2 \cdot \frac{1}{2} \cdot \pi\left(\frac{1}{2} \cdot \text { length of curve } A F B\right) h \approx \frac{7 \pi^{2}}{48} c^{2}
\end{array}\right.
$$

where $c$ is the average size of the pre-existing crack that is the mean air void radius of the asphalt mixture. $A$ is the cross sectional area of the RVE. $t$ is the thickness (height) of the RVE. $\mathrm{V}_{\mathrm{R}}$ is the volume of ADBFC in Figure 3, which is computed by numerical integration of the horizontal cross sectional area of the volume ADBFC through the height of the wing crack. $V_{D}$ is 
determined as the volume of the curved cylinder with changing radius along edges of the wing cracks. $L_{w}$ is the length of the edge of the wing crack (i.e., length of curve ACB) and computed as $L_{w}=\pi(\mathrm{AD})+2(\mathrm{CD}-\mathrm{AD}) \approx 3 c . r_{p}$ is the maximum radius of the curved cylindrical viscoplastic zone. $r_{p}$ is determined as $h \times \pi^{2} / 8 \times\left(\sigma o / \sigma_{m}\right)^{2}[42,43]$, where $\sigma 0$ is the far-field stress applied on a cracked material body (e.g., equivalent horizontal stress caused by the vertical compressive external load) and $\sigma_{m}$ is the maximum yield stress near the crack tip. $r_{p} \approx h / 4=c / 5$ by assuming $\sigma_{0} / \sigma_{m}=1 / 2 . S_{w}$ is the total area of the two surfaces of one wing crack.

\subsection{Crack Initiation Criterion in Compression}

The energy balance principle states that the decreasing rate of potential (stored and recoverable) energy (with respect to crack size) during crack initiation is equal to the rate of dissipated energy due to plastic/viscoplastic deformation and crack opening [44]. In other words, the rate of total energy with respect to crack size equals to zero at the moment of crack initiation. Thus, the following equation is established at the critical moments when the wing cracks are initiated:

$$
\frac{\partial \mathrm{E}}{\partial c}=0
$$

where $\mathrm{E}$ is the total pseudostrain energy that is determined by Equation 3. Solving Equations 3, 4 and 5 yields the crack initiation criterion for asphalt mixtures as below. In fact, Equation 6 can be used as the compressive crack initiation criterion for any viscoelastic materials with preexisting flaws or voids.

$$
R P S E_{c}-\frac{1}{2} D^{2} P S E_{c}=\frac{7}{6} \pi \frac{\Delta G}{c}
$$

where $R P S E_{c}$ and $D P S E_{c}$ are the RPSE and DPSE at the critical moment when the wing cracks are initiated. It must be noted that the crack initiation criterion in Equation 6 defines the energy balance state at and only at the condition when the cracks are initiated, such as at the moment of the compressive strength in the monotonic load tests and at the moment of the flow number in the repeated load tests. Thus the RPSE $E_{c}$ and $D P S E_{c}$ in Equation 6 should be determined at the corresponding moments and the crack size $c$ is also the critical crack size at which the wing cracks are initiated. $\Delta G$ is the bond energy of the viscoelastic material such as asphalt mixtures, which can be regarded as a material property controlling the opening of the cracks in the material.

\section{Test Results Analysis and Discussions}

\subsection{Average Air Voids Size}

Air voids are designed as a necessary part of an asphalt mixture. These air voids are inherent cracks and flaws of the asphalt mixtures and cracks are initiated from these initial air voids due to stress concentration near the edges of air voids. From this point of view, the air void size can be regarded as the critical crack size at which the cracks begin propagating. It is known that a void or crack radius follows a Weibull distribution. In this study, an average air void radius is used as the critical crack size (i.e., $c$ in Equation 6). However, it must be noted that two mixtures with the same average air void radius may have different crack propagation rates because of the variance of the air void or crack size [45].

To determine the average air void radius of asphalt mixtures, X-ray computed tomography (CT) tests are commonly performed on laboratory compacted or field cored cylindrical samples. The system provides X-ray CT images of the cross-section at different depths of the asphalt mixture samples. Then the images are analyzed to differentiate air voids 
from binder mastic and aggregates based on different levels of gray intensity. The air void radius and air void content can be calculated based on the processed image and determined as they vary along the depth of the sample. More details about X-ray CT and image analysis can be found in the literature $[46,47]$. By collecting and analyzing the X-ray CT data of the laboratory compacted asphalt mixture samples [48-50] and field asphalt pavement layer cores [51], the relationship between average air void radius and air void content is presented in Figure 4.

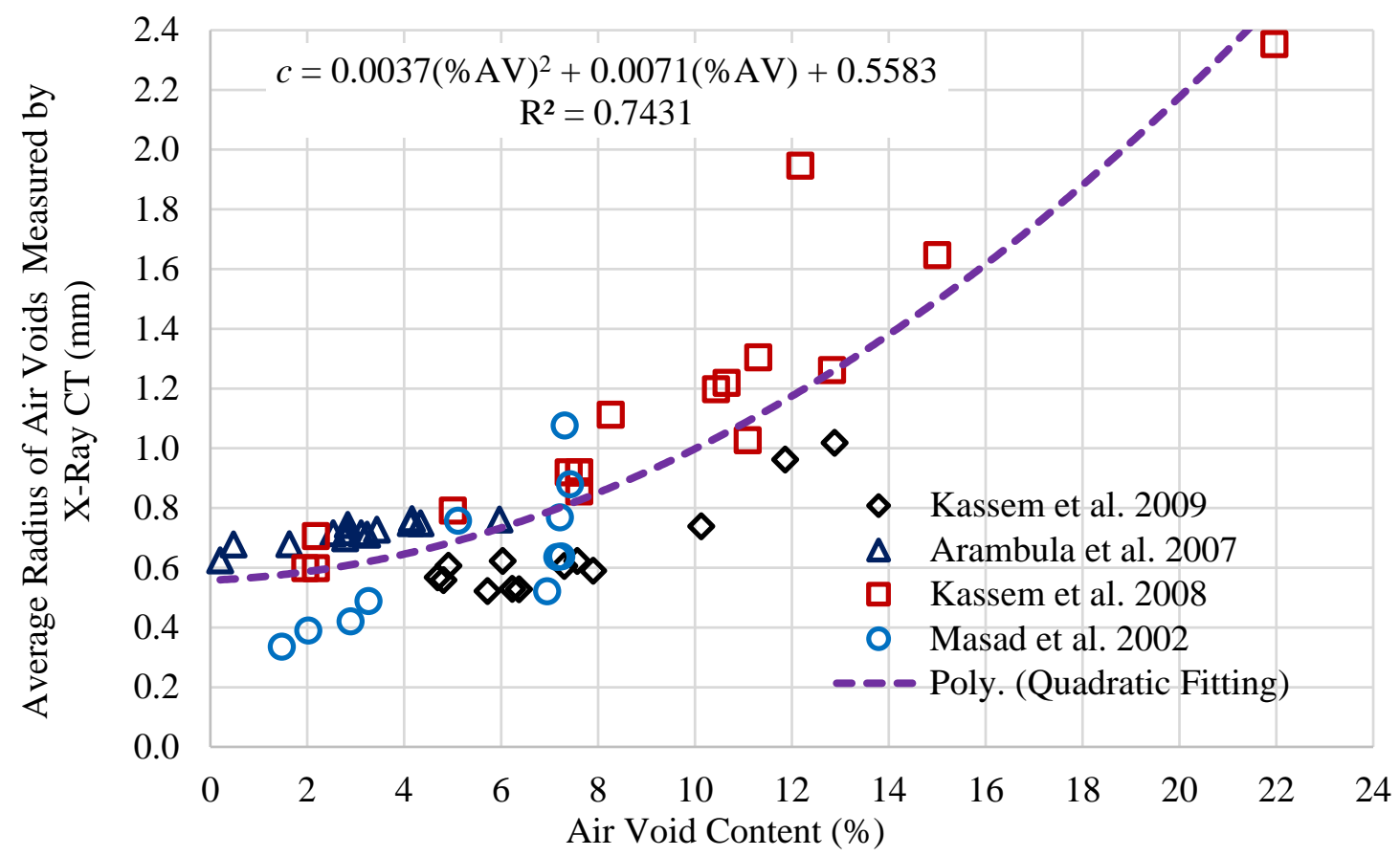

Fig.4. Relationship between average air void radius and air void content of asphalt mixtures including both laboratory and field samples.

In general, Figure 4 indicates that the average air void radius increases when the air void content increases and the regression relation is as below.

$$
c=0.0037(\% A V)^{2}+0.0071(\% A V)+0.5583 \quad R^{2}=0.7431
$$

where $c$ is the average air void radius that is also the critical crack size, mm; \%AV is air void content in percentage. Equation 7 indicates the minimum average air void radius is $0.5583 \mathrm{~mm}$. It is noted that the minimum average air void radius can be smaller than $0.5583 \mathrm{~mm}$ as some of the small air voids may not be detected due to the resolution limitation of the X-ray CT. In this study, Equation 7 is used to estimate the critical crack size based on the air void content of the asphalt mixtures. For example, the asphalt mixtures with $4 \%$ and $7 \%$ air void contents correspond to average critical crack size of $0.65 \mathrm{~mm}$ and $0.79 \mathrm{~mm}$, respectively.

\subsection{Bond Energy of Asphalt Mixtures and its Decomposition}

The bond energy of asphalt mixtures (i.e., $\Delta \mathrm{G}$ ) is determined through crack initiation criterion in Equation 6. The critical RPSE and DPSE are calculated at the peak stress of the strength test (based on Figure 1) and the average crack sizes are determined by Equation 7. Figure 5 shows the values of the bond energy of the tested asphalt mixtures in Table 1 . It is found that the bond energy of asphalt mixtures increases with aging period and loading rate and 
it decreases with temperature. The bond energy of asphalt mixtures does not show a consistent change with air void content and the binder type.

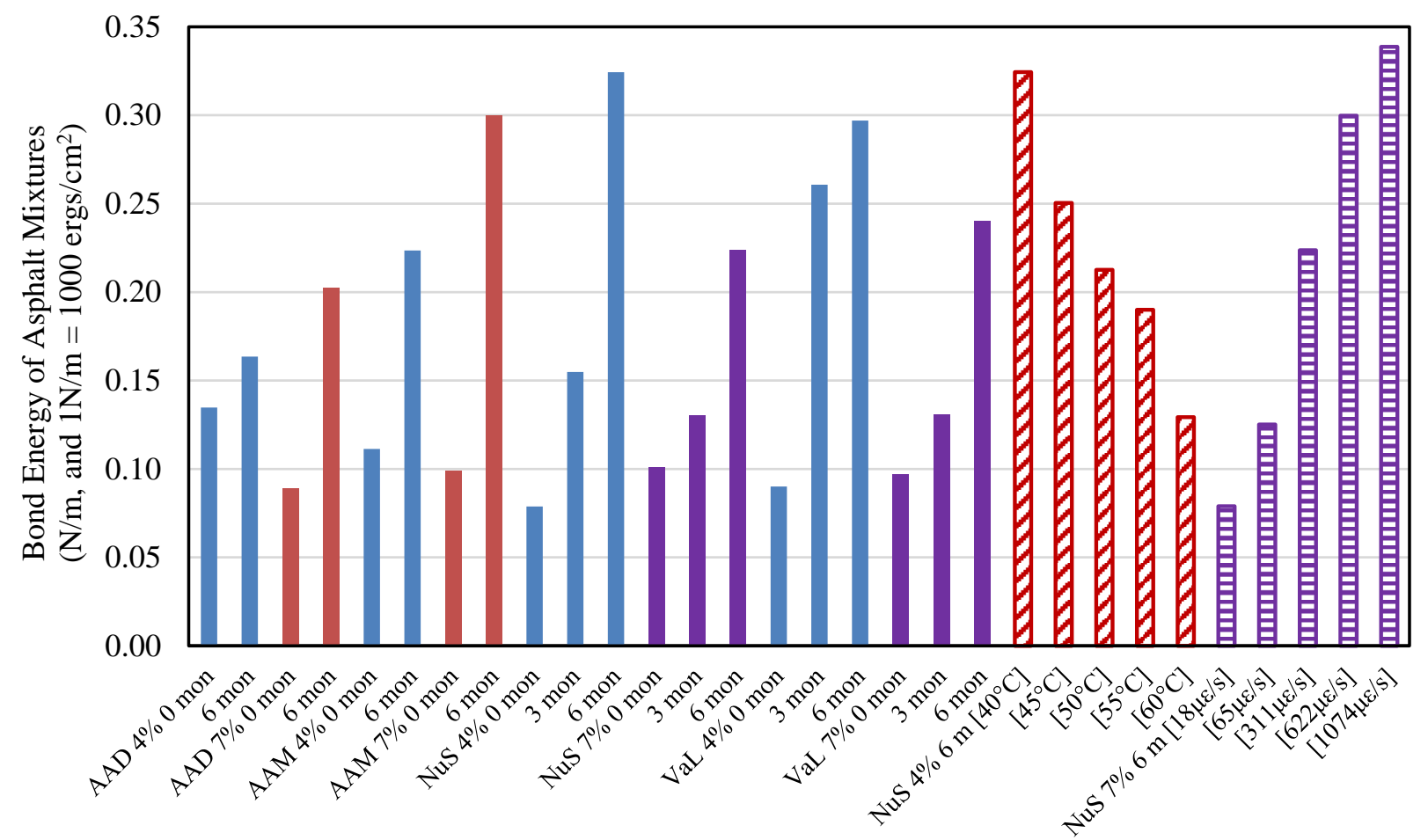

Fig. 5. Bond energy of asphalt mixtures determined using crack initiation criterion.

The bond energy of an asphalt mixture is an important property that dominates the crack initiation and propagation processes. It is known that the bond energy can be cohesive bond energy when the crack occurs within single material phase or adhesive bond energy when the crack propagates along the interface of two material phases, which are expressed as below [52]:

$$
\left\{\begin{array}{l}
\Delta G_{i}^{c}=2 \gamma_{i}=2\left(\gamma_{i}^{L W}+\gamma_{i}^{A B}\right)=2\left(\gamma_{i}^{L W}+2 \sqrt{\gamma_{i}^{+} \gamma_{i}^{-}}\right) \\
\Delta G_{i j}^{a}=2\left(\gamma_{i}+\gamma_{j}-\gamma_{i j}\right)=2 \sqrt{\gamma_{i}^{L W} \gamma_{j}^{L W}}+2 \sqrt{\gamma_{i}^{+} \gamma_{j}^{-}}+2 \sqrt{\gamma_{i}^{-} \gamma_{j}^{+}}
\end{array}\right.
$$

where $\Delta G_{i}^{c}$ and $\Delta G_{i j}^{a}$ are cohesive and adhesive bond energy, respectively. The subscript $i$ and $j$ stand for material $i$ (e.g., asphalt mastic) and material $j$ (e.g., aggregate). $\gamma_{i}$ is surface free energy of the material $i, \gamma_{i}^{L W}$ is the Lifshitz-van der Waals (LW) surface energy component of the material $i, \gamma_{i}^{A B}$ is the acid-base (AB) surface energy component of the material $i, \gamma_{i}^{+}$and $\gamma_{i}^{-}$are the Lewis acid and base components of the material $i . \gamma_{i j}$ is the interfacial surface free energy between material $i$ and material $j$.

According to the study in the literature [53], fracture in asphalt mixtures can occur within the asphalt (cohesive fracture) or at the aggregate-asphalt interface (adhesive fracture), which depends on the asphalt binder property, the asphalt film thickness and the loading rate. Cohesive fracture is preferred in thick asphalt films whereas adhesive fracture is preferential in thinner asphalt film. Since the film thicknesses vary in the asphalt mixtures, adhesive and cohesive fracture can occur simultaneously in one asphalt mixture. Therefore, the bond energy in Equation 
6 is neither a pure cohesive bond energy of asphalt nor a pure adhesive bond energy between asphalt and aggregates, but an integrated representative bond energy of the cohesive and adhesive fracture. The bond energy of asphalt mixtures represents combined bond energy for the cohesive fracture and the adhesive fracture. A decomposition of the bond energy of the asphalt mixture is formulated as below:

$$
\Delta G=\alpha \cdot \Delta G^{c}+(1-\alpha) \Delta G^{a}
$$

where $\Delta G^{c}$ is the cohesive bond energy within the asphalt, $\Delta G^{a}$ is the adhesive bond energy at the asphalt-aggregate interface, $\alpha$ is a weight factor of the cohesive bond energy that varies from 0 to 1 , which can also be interpreted as the percentage of cohesive fracture in an asphalt mixture. It is noted that the cohesive fracture within aggregates was not considered as relatively high temperatures $\left(40^{\circ} \mathrm{C}\right.$ and above) were used in this study and cracks through the aggregates were not observed in the tests. However, the laboratory tests at intermediate or low temperatures show the fracture/rupture through the aggregates (limestone is more severe), which may affect the decomposition of bond energy and needs a further study.

Equation 9 indicates that $\Delta G^{c}<\Delta G<\Delta G^{a}$ applies to an asphalt mixture since $\Delta G^{c}<\Delta G^{a}$. Studies in the literature show that the cohesive bond energy (i.e., $\Delta G^{c}$ ) normally ranges from 30 to $100 \mathrm{ergs} / \mathrm{cm}^{2}\left(1 \mathrm{ergs} / \mathrm{cm}^{2}=0.001 \mathrm{~N} / \mathrm{m}\right)$ and the adhesive bond energy (i.e., $\Delta G^{a}$ ) varies between 80 and $300 \mathrm{ergs} / \mathrm{cm}^{2}$ [52-55]. Figure 5 shows that the bond energy values of asphalt mixtures back-calculated using the crack initiation criterion varies between 50 and 350 ergs $/ \mathrm{cm}^{2}$, which are fairly consistent with the measurements in the literature.

Equation 9 also indicates that a lower bond energy of an asphalt mixture (i.e., lower $\Delta G$ ) is caused by a higher percentage of cohesive fracture and vice versa. Based on this, a further conclusion can be drawn from Figure 5 that asphalt mixtures will have a greater percentage of cohesive fracture when the bond energy of the asphalt mixture is lower such as a shorter aging time, a higher temperature or a lower loading rate. This is attributed to that the asphalt binder dominates a mixtures' fracture behavior in such conditions that the mixtures are softer and cracks are inclined to propagate through the asphalt film.

The percentages of the cohesive fracture and the adhesive fracture can be determined by Equation 9 if the cohesive and adhesive bond energy are known. The surface energy components for the binders (including AAD-1, AAM-1, NuS and VaL) and the aggregates (i.e., Texas limestone) used in this study had been measured using the Wilhelmy plate device and the universal sorption device, respectively, in the previous studies performed at Texas A\&M University $[52,56]$ and the recent test results from ARC researchers. Based on these data, the cohesive bond energy and adhesive bond energy for the tested asphalt mixtures were calculated using Equation 8 and are shown in Table 2. Then using the bond energy of the asphalt mixtures, the percentage of cohesive fracture (i.e., $\alpha$ ) was calculated by Equation 9 and the results are also provided in Table 2. The bond energy of the aged asphalt mixtures were not obtained because the surface energy measurements of the aged binders were not available in the previous studies.

\section{Table 2}

Surface Energy Components and Decomposition of Bond Energy of Asphalt Mixtures.

\begin{tabular}{|c|c|c|c|c|c|c|c|c|c|c|}
\hline \multirow{2}{*}{ Materials } & \multicolumn{5}{|c|}{$\begin{array}{c}\text { Surface energy components }{ }^{(\mathbf{1})} \\
\left(\mathrm{ergs} / \mathrm{cm}^{2}\right)\end{array}$} & $\begin{array}{l}\text { Cohesive } \\
\text { bond } \\
\text { energy }^{(2)}\end{array}$ & $\begin{array}{c}\text { Adhesive } \\
\text { bond } \\
\text { energy }^{(2)}\end{array}$ & $\begin{array}{l}\text { Asphalt } \\
\text { mixtures }\end{array}$ & $\begin{array}{c}\text { Bond energy } \\
\text { of asphalt } \\
\text { mixtures }\end{array}$ & $\begin{array}{l}\text { Percentage } \\
\text { of cohesive } \\
\text { fracture }^{(4)}\end{array}$ \\
\hline & $\Gamma^{+}$ & $\Gamma^{-}$ & $\Gamma^{\mathrm{AB}}$ & $\Gamma^{\mathrm{LW}}$ & $\Gamma$ & $\begin{array}{c}\Delta \mathrm{G}^{c} \\
\left(\mathrm{ergs} / \mathrm{cm}^{2}\right)\end{array}$ & $\begin{array}{c}\Delta \mathrm{G}^{a} \\
\left(\mathrm{ergs} / \mathrm{cm}^{2}\right)\end{array}$ & $\begin{array}{c}\text { Sample } \\
\text { Label }\end{array}$ & $\begin{array}{c}\Delta \mathrm{G} \\
\left(\mathrm{ergs} / \mathrm{cm}^{2}\right)\end{array}$ & $\alpha$ \\
\hline
\end{tabular}




\begin{tabular}{|c|c|c|c|c|c|c|c|c|c|c|}
\hline \multirow{2}{*}{ AAD-1 } & \multirow{2}{*}{5.96} & \multirow{2}{*}{14.48} & \multirow{2}{*}{18.58} & \multirow{2}{*}{8.59} & \multirow{2}{*}{27.17} & \multirow{2}{*}{54.3} & \multirow{2}{*}{149.8} & $\begin{array}{c}\mathrm{AAD} 4 \% \\
\text { mon* }\end{array}$ & 134.7 & $16 \%$ \\
\hline & & & & & & & & $\begin{array}{c}\mathrm{AAD} 7 \% 0 \\
\text { mon }\end{array}$ & 88.9 & $64 \%$ \\
\hline \multirow{2}{*}{ AAM-1 } & \multirow{2}{*}{17.79} & \multirow{2}{*}{21.40} & \multirow{2}{*}{39.02} & \multirow{2}{*}{9.33} & \multirow{2}{*}{48.35} & \multirow{2}{*}{96.7} & \multirow{2}{*}{224.0} & $\begin{array}{c}\text { AAM } 4 \% 0 \\
\text { mon }\end{array}$ & 111.3 & $89 \%$ \\
\hline & & & & & & & & $\begin{array}{c}\text { AAM 7\% } 0 \\
\text { mon }\end{array}$ & 98.7 & $98 \%$ \\
\hline \multirow{2}{*}{ NuStar } & \multirow{2}{*}{0.79} & \multirow{2}{*}{2.85} & \multirow{2}{*}{3.00} & \multirow{2}{*}{43.07} & \multirow{2}{*}{46.07} & \multirow{2}{*}{92.1} & \multirow{2}{*}{138.4} & $\begin{array}{c}\mathrm{NuS} \mathrm{4 \%} 0 \\
\text { mon }\end{array}$ & 78.7 & $\begin{array}{c}129 \% \\
(100 \%)\end{array}$ \\
\hline & & & & & & & & $\begin{array}{c}\mathrm{NuS} \mathrm{7 \%} 0 \\
\text { mon }\end{array}$ & 100.8 & $81 \%$ \\
\hline \multirow{2}{*}{ Valero } & \multirow{2}{*}{0.00} & \multirow{2}{*}{4.62} & \multirow{2}{*}{0.00} & \multirow{2}{*}{42.87} & \multirow{2}{*}{42.87} & \multirow{2}{*}{85.7} & \multirow{2}{*}{103.9} & \begin{tabular}{|c|} 
VaL 4\% 0 \\
mon
\end{tabular} & 90.1 & $76 \%$ \\
\hline & & & & & & & & \begin{tabular}{|c|}
$\begin{array}{c}\text { VaL 7\% } 0 \\
\text { mon }\end{array}$ \\
\end{tabular} & 96.7 & $40 \%$ \\
\hline $\begin{array}{l}\text { Lime- } \\
\text { stone }\end{array}$ & 1.27 & 393.65 & 44.72 & 57.25 & 101.97 & 203.9 & NA & NA & NA & NA \\
\hline \multicolumn{11}{|c|}{$\begin{array}{l}\text { (1) Surface energy components of the binders and aggregate were measured in previous studies at Texas A\&M } \\
\text { University [52, 56] and ARC researchers at Texas A\&M Transportation Institute; } \\
\text { (2) Calculated by Equation } 8 \text { based on the test data of the surface energy components for binders and aggregate; } \\
\text { (3) Back-calculated by crack initiation criterion in Equation } 6 \text { and the compressive strength tests results. } \\
\text { (4) Calculated by Equation } 9 \text { using cohesive, adhesive bond energy and bond energy of asphalt mixtures } \\
\text { * "mon" stands for "month" that is the length of the aging period }\end{array}$} \\
\hline
\end{tabular}

Take one asphalt mixture (AAD 7\% 0 mon in Table 2) as an example, $\alpha=0.64$ means that $64 \%$ of the cracking of this asphalt mixture was cohesive fracture and the remaining $36 \%$ was the adhesive fracture. It is noted that one asphalt mixture (NuS $4 \% 0$ month aging in Table 2) has a percentage of cohesive fracture more than $100 \%$, which is due to that the back-calculated bond energy is less than the cohesive bond energy. The reasons for this result can be from many factors, such as inaccurate measurement of surface energy components and/or bond energy of the mixture. The percentage of the cohesive fracture was corrected to $100 \%$ for the case that $\Delta G<\Delta G^{c}$ and $0 \%$ for the case that $\Delta G^{a}<\Delta G$.

\subsection{Simplification of Crack Initiation Criterion}

The crack initiation criterion in Equation 6 is expressed in terms of energy (e.g., DPSE and RPSE) which need to be determined by integrating stress over pseudostrain history. This calculation is complicated and not suitable for practical implementation of the crack initiation criterion. The following shows a simplification of Equation 6 based on an analysis of the test results. To simplify Equation 6, a critical energy ratio $(\eta)$ is defined as:

$$
\eta=\frac{R P S E_{c}-\frac{1}{2} D P S E_{c}}{R P S E_{c}}
$$

where $R P S E_{c}$ and $D P S E_{c}$ are the critical RPSE and DPSE, respectively. For example, in a monotonic load test, the $R P S E_{c}$ and $D P S E_{c}$ are determined as: 


$$
\left\{\begin{array}{l}
\operatorname{RPSE}_{c}=\frac{\sigma_{u}^{2}}{2 E_{R}} \\
D P S E_{c}=\int_{0}^{t_{c}} \sigma \frac{d \varepsilon^{R}}{d \tau} d \tau-R P S E_{c}
\end{array}\right.
$$

where $\sigma_{u}$ is the compressive strength that is also the peak stress on a stress-strain curve, $E_{R}$ is reference modulus that is assigned as Young's modulus or elastic modulus of the mixture, $t_{c}$ is critical time when $\sigma_{u}$ occurs, $\sigma$ is the measured stress history before $t_{c}, \tau$ is the time history before $t_{c}$.

The critical energy ratio was determined using stress-pseudostrain curve (e.g., Figure 1) and Equations 10 and 11 for all of the tested asphalt mixtures. It is found from Figure 6 that the critical energy ratio does not vary significantly for different asphalt mixtures at different temperatures and loading rates. The mean value of the critical energy ratio for all of the measurements is 0.6622 that is approximately equal to $2 / 3$. The standard deviation of the critical energy ratio is 0.0195 and the coefficient of variation $(\mathrm{COV})$ is $3 \%$. As a result, the crack initiation criterion is simplified as below by substituting Equations 10 and 11 in Equation 6 and using $2 / 3$ as the critical energy ratio.

$$
\sigma_{u}=\sqrt{\frac{7}{2} \pi \frac{\Delta G \cdot E_{R}}{c}}
$$

Equation 12 shows a direct relation of the compressive strength $\left(\sigma_{u}\right)$ with the bond energy $(\Delta G)$, elastic modulus $\left(E_{R}\right)$ and critical crack size $(c)$. Equation 12 can be regarded as a companion equation for the tensile strength of the mode I cracking of an elastic material as shown follows:

$$
\sigma_{u}^{T}=\sqrt{\frac{G_{I} \cdot E}{\pi c}}
$$

where $\sigma_{u}^{T}$ is tensile strength, $G_{I}$ is the energy release ratio of mode I fracture, $E$ is the elastic modulus, $c$ is the critical crack size. The differences between Equation 12 and Equation 13 are the coefficients involved in the equations, which is due to the differences of the configuration of the propagated cracks. In compression, the new crack tends to grow in the direction of the external compressive load and forms the wing cracks as shown in Figures 2 and 3. In tension, the new crack tends to propagate in the direction normal to the external tensile load and elongates the existing crack. A different new crack configuration leads to a different material volume releasing the energy, which results in different prediction equations for compressive and tensile strength, as shown in Equations 12 and 13. 


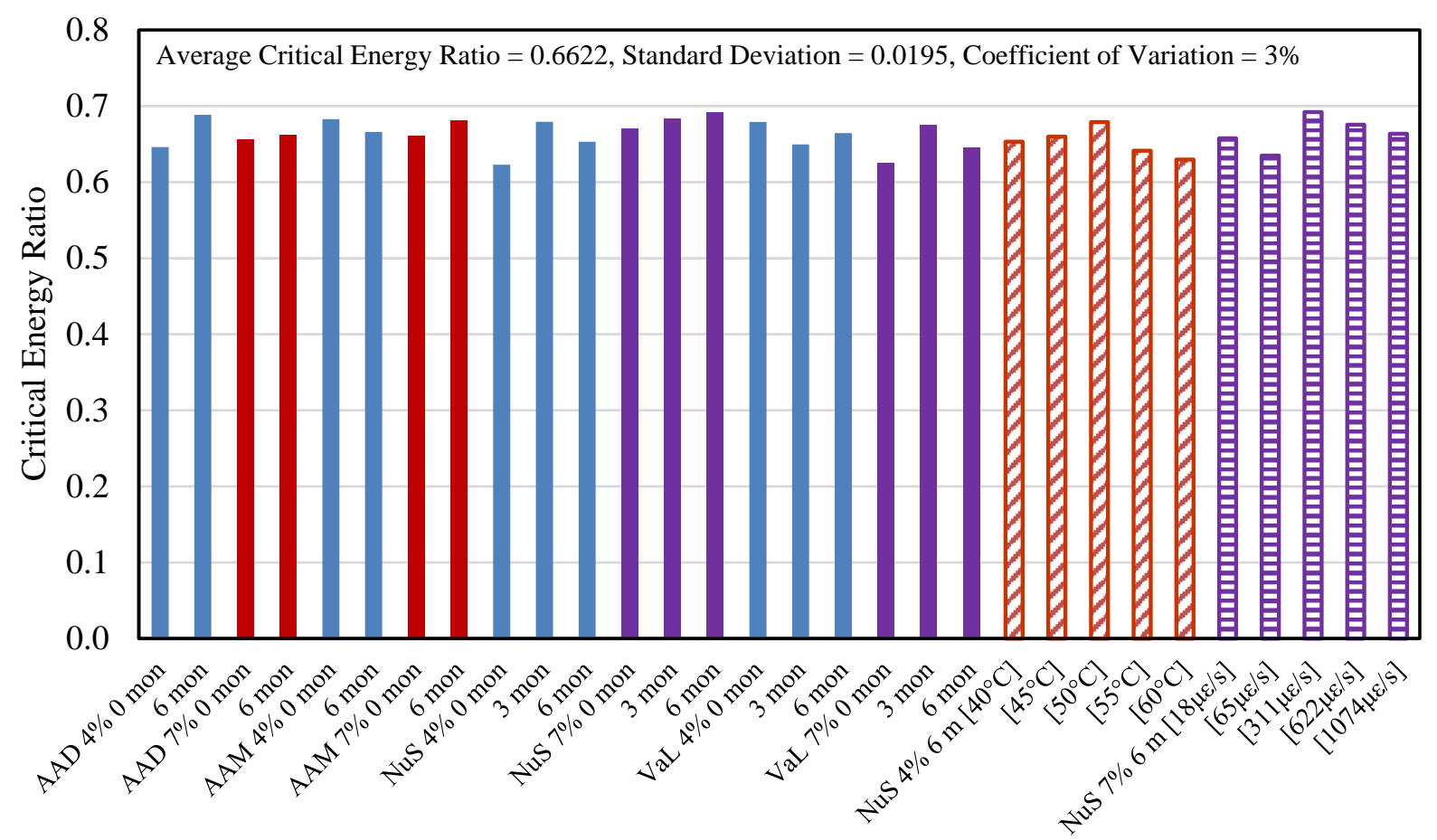

Fig. 6. Critical energy ratio for different asphalt mixtures at different conditions.

\subsection{Implementation in Predictions of Compressive Strength}

Equation 12 provides a convenient method to predict the compressive strength or bond energy of asphalt mixtures once the other is given. To validate the crack initiation criterion, Equation 12 is used to analyze the compressive strength test data reported in the literature [57]. Tables A1 and A2 (attached as Appendix A) from the literature reported the compressive strength test results at four confining pressure levels $(0,69,138,207 \mathrm{kPa})$ and five loading rate levels $\left(0.00001,0.0001,0.002,0.0042,0.0071 \mathrm{sec}^{-1}\right)$, respectively. The six types of the tested mixtures included two Kansas mixtures (KS-1 and KS-2), two Missouri mixtures (MO-1 and MO-2) and two Iowa mixtures (IA-1 and IA-2). The measured test data included air void content, initial yield stress, failure stress (i.e., compressive strength), and the elastic modulus for the six asphalt mixtures.

The air void content for each of the asphalt mixtures is first converted to air void radius that is also the critical crack size using the regression relation in Equation 7. The bond energy for each mixture is then calculated using Equation 12 based on the uniaxial compressive strength test data in Table A1. It is noted that the "elastic moduli" (all less than $150 \mathrm{MPa}$ at $35^{\circ} \mathrm{C}$ ) reported in Tables A1 and A2 are very low compared with the common understanding of the asphalt concrete's modulus (e.g., greater than $1000 \mathrm{MPa}$ ) at $35^{\circ} \mathrm{C}$. This is because the "elastic moduli" were computed as the slope of the linear part of the stress-strain curve in the compressive strength tests. However, the measured strain included both elastic strain and viscous strain. A correct elastic modulus should be the ratio of stress to elastic strain. Thus the "elastic moduli" shown in Tables A1 and A2 are not the accurate elastic moduli for the six mixtures. Instead, the elastic modulus for each of the mixtures was obtained through back-calculating falling weight deflectometer (FWD) data and determined as 3115, 1619, 2410, 437, 494, $1869 \mathrm{MPa}$ for mixtures KS-1, KS-2, MO-1, MO-2, IA-1, IA-2, respectively [57]. 
Figure 7 shows the calculated bond energy values at different loading rates for each of the six mixtures, which are determined by Equation 12 and using the FWD back-calculated elastic moduli and the test data in Table A1. It is found that the bond energy of the six asphalt mixtures varies from 0.03 to $0.35 \mathrm{~N} / \mathrm{m}$ and the bond energy increases with the loading rates, which are consistent with the measured results for the asphalt mixtures tested in this study that are shown in Figure 5.

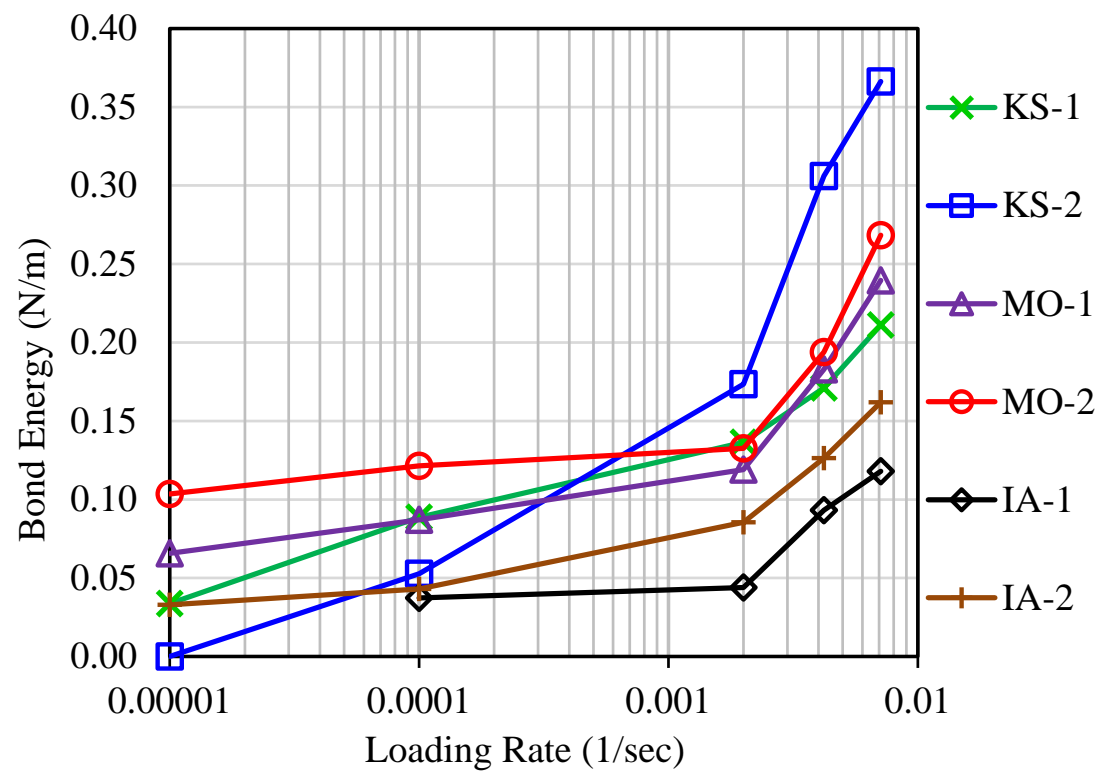

Fig. 7. Bond energy of six different asphalt mixtures at various loading rates determined based on the uniaxial compressive strength test data.

The bond energy at the loading rate of $0.0001 / \mathrm{sec}$ are employed in Equation 12 to predict the triaxial compressive strength of the six asphalt mixtures at different confining pressures, which are compared with the measured results of the compressive strength shown in Table A2. Figure 8 illustrates the comparisons and indicates the consistency between the predictions and the measurements. This validates the simplified crack initiation criterion in Equation 12 for the asphalt mixtures in the uniaxial and triaxial compression strength tests.

A number of future studies are needed following on this research work. The first study is to validate the hypotheses used in this paper including 1) the slope of the stress-pseudostrain line during unloading is identical to the loading slope that is Young's modulus, which is currently under validation using loading-unloading tests; 2) the air voids are assumed to be the pre-existing cracks that have a circular penny shape due to the compression of the external loads; and 3) the maximum size of viscoplastic zone near the tips of wing cracks is determined by assuming the far-field horizontal stress resulting from external compressive load is half of the yield stress. These assumptions were proposed based on hypothesized derivations for asphalt mixtures. Nevertheless, the consistency between the test results of this paper and the measurements in the literature have preliminarily validated the compressive crack initiation theory developed in this study. The second future study is to implement the crack initiation criterion in different loading conditions such as repeated compressive loads and to predict the flow number or flow time based on the crack initiation criterion of the asphalt mixtures. 


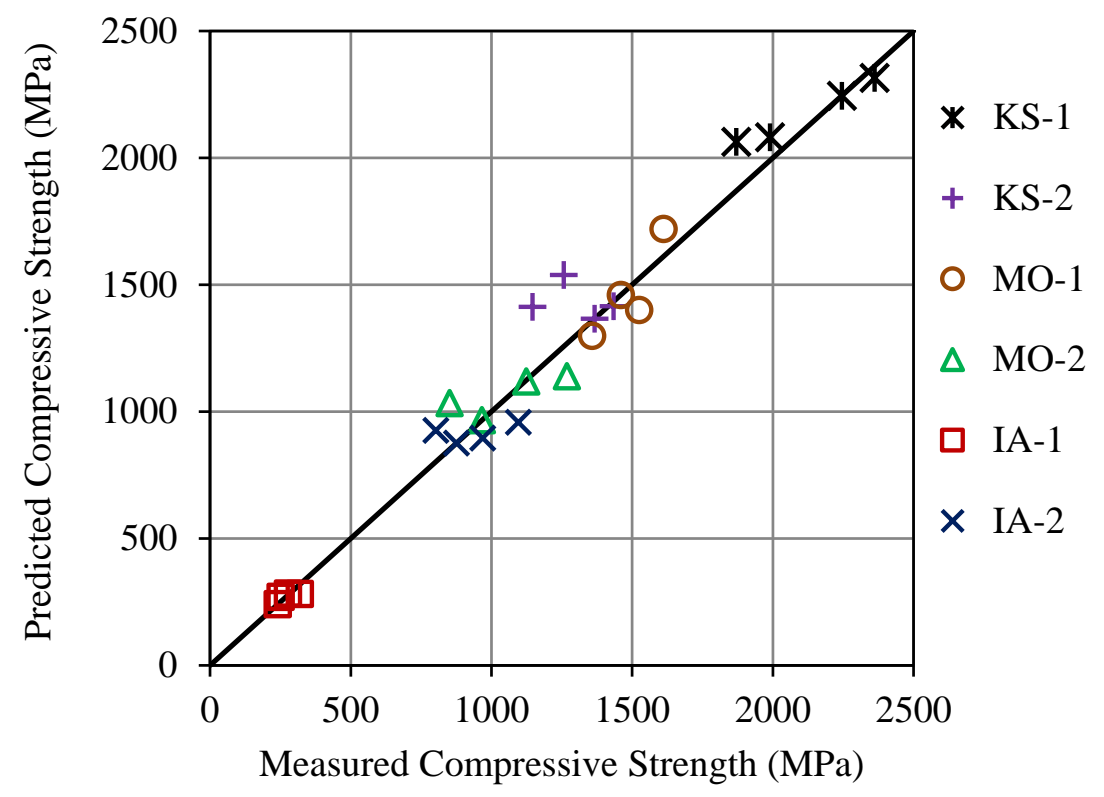

Fig. 8. Comparison between predicted compressive strength using simplified crack initiation criterion and the measured compressive strength at different confining pressures.

\section{Summaries and Conclusions}

Asphalt mixtures exhibit overstress softening under a monotonic compressive load and a "tertiary flow" under a repeated compressive load, both of which were modeled using a characterizing damage parameter by the existing models in the literature. The physics of the damage was not explicitly defined and mechanistically modeled in these models, especially under compressive loads. The authors' previous studies indicated that the damage of asphalt mixtures in compression mainly resulted from the growth of air voids and microcracks in addition to viscoplastic deformation. In this paper, crack initiation of asphalt mixtures under external compressive loads was studied using fracture mechanics. Summaries and conclusions based on the theoretical and laboratory work performed in this study are presented as follows:

(1) Cracks in compression are inclined to grow in the direction of the external compressive loads. The wing cracks are where the new cracks grow in compression. They are driven by the localized tensile or shear stresses near the tips of and parallel to the pre-existing cracks which are the compressed air voids in asphalt mixtures.

(2) A crack initiation criterion was developed for asphalt mixtures under compressive loads based on the energy balance principle of fracture mechanics. Pseudostrain energy was used in the principle to eliminate the viscous energy dissipation. Critical crack size was estimated by a quadratic regression relation in terms of the air void content of the asphalt mixtures.

(3) The bond energy of the asphalt mixtures was back-calculated using the crack initiation criterion and the compressive strength test data. It was found that the bond energy of asphalt mixtures increased with the aging period and loading rate and decreased with temperature.

(4) The bond energy of the asphalt mixtures was an integrated representative bond energy of the cohesive and adhesive fracture occurring simultaneously in the mixture. The percentages of cohesive fracture and adhesive fracture were determined based on the 
bond energy of the asphalt mixtures and the individual surface energy of the asphalt binders and aggregates.

(5) The crack initiation criterion was simplified to correlate the compressive strength with the bond energy, critical crack size (i.e., air void content) and Young's modulus of the mixtures. Compressive strength test data in the literature were utilized to validate the crack initiation criterion. The compressive strength of the mixtures were predicted and consistency was found between the predictions and measurements.

\section{Appendix A. Compressive Strength Test Data}

Table A1 Uniaxial Compressive Strength Test Results at Different Loading Rates

\begin{tabular}{|c|c|c|c|c|c|}
\hline Sample ID & Air void (\%) & $\begin{array}{l}\text { Loading Rate } \\
\left(\sec ^{-1}\right)\end{array}$ & $\begin{array}{l}\text { Initial yield } \\
\text { stress (kPa) }\end{array}$ & $\begin{array}{c}\text { Failure } \\
\text { Strength } \\
(\mathrm{kPa})\end{array}$ & $\begin{array}{c}\text { Elastic } \\
\text { Modulus } \\
\text { (MPa) }\end{array}$ \\
\hline KS-1 & 6.12 & 0.00001 & 526.02 & 992.7 & 53.4 \\
\hline $\mathrm{KS}-1$ & 6.51 & 0.0001 & 1094.5 & 1870 & 74.03 \\
\hline KS-1 & 6.26 & 0.002 & 1504.73 & 2843.4 & 109.21 \\
\hline KS-1 & 6.51 & 0.0042 & 1991.77 & 3058.5 & 102.65 \\
\hline KS-1 & 6.46 & 0.0071 & 2027.94 & 3058.5 & 142.86 \\
\hline KS-2 & 7.25 & 0.00001 & 484.76 & 664.1 & 36.2 \\
\hline KS-2 & 6.71 & 0.0001 & 981.62 & 1145.5 & 57.14 \\
\hline KS-2 & 6.56 & 0.002 & 1493.95 & 2256.2 & 66.67 \\
\hline KS-2 & 6.95 & 0.0042 & 1686.77 & 2672.5 & 54.54 \\
\hline $\mathrm{KS}-2$ & 6.50 & 0.0071 & 2152.66 & 2846 & 100 \\
\hline MO-1 & 8.97 & 0.00001 & 416.16 & 721.5 & 27.4 \\
\hline MO-1 & 9.42 & 0.0001 & 587.42 & 1211.4 & 106.81 \\
\hline MO-1 & 9.08 & 0.002 & 1063.93 & 2110.5 & 130.45 \\
\hline MO-1 & 9.46 & 0.0042 & 1128.78 & 2365 & 110 \\
\hline MO-1 & 9.16 & 0.0071 & 1932 & 2902.4 & 123.43 \\
\hline MO-2 & 7.41 & 0.00001 & 343.49 & 784 & 31.44 \\
\hline MO-2 & 7.19 & 0.0001 & 520.58 & 851.4 & 31.07 \\
\hline MO-2 & 7.29 & 0.002 & 688.83 & 1439 & 81.93 \\
\hline MO-2 & 6.96 & 0.0042 & 994.65 & 1953.4 & 100.75 \\
\hline MO-2 & 7.50 & 0.0071 & 1913.99 & 2577.5 & 131.97 \\
\hline IA-1 & 7.00 & 0.0001 & 74.12 & 240.9 & 6.35 \\
\hline IA-1 & 6.94 & 0.002 & 230.23 & 665.7 & 40.94 \\
\hline IA-1 & 6.72 & 0.0042 & 367.39 & 864.4 & 32.06 \\
\hline IA-1 & 6.72 & 0.0071 & 544.29 & 986.7 & 32.97 \\
\hline IA-2 & 7.38 & 0.00001 & 378.15 & 605.3 & 27.48 \\
\hline IA-2 & 7.90 & 0.0001 & 397.12 & 802.5 & 38.5 \\
\hline IA-2 & 7.63 & 0.002 & 630.55 & 1561.6 & 71.8 \\
\hline IA-2 & 7.38 & 0.0042 & 1145.11 & 2095.7 & 85.81 \\
\hline IA-2 & 7.86 & 0.0071 & 1508.74 & 2368 & 88.66 \\
\hline
\end{tabular}

Table A2 Triaxial Compressive Strength Test Results at Different Confining Pressures and at a Loading Rate of $0.0001 / \mathrm{sec}$ 


\begin{tabular}{|c|c|c|c|c|c|}
\hline Sample ID & Air void (\%) & $\begin{array}{c}\text { Confining } \\
\text { pressure (kPa) }\end{array}$ & $\begin{array}{c}\text { Initial yield } \\
\text { stress (kPa) }\end{array}$ & $\begin{array}{c}\text { Failure } \\
\text { Strength } \\
\text { (kPa) }\end{array}$ & $\begin{array}{c}\text { Elastic } \\
\text { Modulus } \\
\text { (MPa) }\end{array}$ \\
\hline KS-1 & 6.51 & 0 & 1094.5 & 1870 & 66.48 \\
\hline KS-1 & 6.64 & 69 & 1486.66 & 1990 & 68.29 \\
\hline KS-1 & 6.73 & 138 & 1567.62 & 2245 & 79.98 \\
\hline KS-1 & 6.46 & 207 & 1650.02 & 2361.1 & 83.38 \\
\hline KS-2 & 6.71 & 0 & 919.84 & 1145.5 & 57.14 \\
\hline KS-2 & 6.49 & 69 & 975.01 & 1256.6 & 66.67 \\
\hline KS-2 & 6.99 & 138 & 1120.44 & 1366.3 & 54.54 \\
\hline KS-2 & 6.66 & 207 & 1200.77 & 1433.6 & 57.14 \\
\hline MO-1 & 9.42 & 0 & 384.39 & 1211.4 & 90.45 \\
\hline MO-1 & 9.57 & 69 & 617.43 & 1357.8 & 52.18 \\
\hline MO-1 & 9.68 & 138 & 604.22 & 1459.4 & 66.5 \\
\hline MO-1 & 9.61 & 207 & 864.76 & 1525.1 & 60.91 \\
\hline MO-2 & 7.19 & 0 & 520.58 & 851.4 & 31.07 \\
\hline MO-2 & 7.43 & 69 & 558.86 & 966 & 27.63 \\
\hline MO-2 & 6.53 & 138 & 619.86 & 1123.5 & 34.68 \\
\hline MO-2 & 6.93 & 207 & 792.47 & 1268.3 & 37 \\
\hline IA-1 & 7.00 & 0 & 74.12 & 240.9 & 6.35 \\
\hline IA-1 & 7.56 & 69 & 86.55 & 250.8 & 8.3 \\
\hline IA-1 & 7.62 & 138 & 116.96 & 276.7 & 9.21 \\
\hline IA-1 & 7.66 & 207 & 122.88 & 319 & 9.08 \\
\hline IA-2 & 7.90 & 0 & 397.12 & 802.5 & 38.5 \\
\hline IA-2 & 7.91 & 69 & 561.79 & 875.8 & 34.5 \\
\hline IA-2 & 7.93 & 138 & 625.4 & 968.8 & 36.12 \\
\hline IA-2 & 8.00 & 207 & 749.74 & 1095.6 & 41.54 \\
\hline & & & & & \\
\hline
\end{tabular}

\section{References}

[1] Schapery RA. Correspondence principles and a generalized j-integral for large deformation and fracture analysis of viscoelastic media. International Journal of Fracture. 1984;25(3):195-223.

[2] Schapery RA. A theory of mechanical behavior of elastic media with growing damage and other changes in structure. Journal of the Mechanics and Physics of Solids. 1990;38(2):215-53.

[3] Schapery RA. Nonlinear viscoelastic and viscoplastic constitutive equations with growing damage. International Journal of Fracture. 1999;97(1-4):33-66.

[4] Kim YR, Lee YC, Lee HJ. Correspondence principle for characterization of asphalt concrete. Journal of Materials in Civil Engineering. 1995;7(1):59-68.

[5] Park SW, Kim YR, Schapery RA. Viscoelastic continuum damage model and its application to uniaxial behavior of asphalt concrete. Mechanics of Materials. 1996;24(4):241-55.

[6] Lee HJ, Kim YR, Kim SH. Viscoelastic constitutive modeling of asphalt concrete with growing damage. Structural Engineering and Mechanics. 1999;7(2):225-40.

[7] Chehab GR, Kim YR, Schapery RA, Witczak MW, Bonquist R. Characterization of asphalt concrete in uniaxial tension using a viscoelastoplastic continuum damage model. Journal of the Association of Asphalt Paving Technologists. 2003;72:315-55.

[8] Underwood S, Kim R. Viscoelastoplastic continuum damage model for asphalt concrete in tension. Journal of Engineering Mechanics. 2011;137(11):732-9. 
[9] Uzan J. Viscoelastic-viscoplastic model with damage for asphalt concrete. Journal of Materials in Civil Engineering. 2005;17(5):528-34.

[10] Gibson NH, Schwartz CW, Schapery RA, Witczak MW. Viscoelastic, viscoplastic, and damage modeling of asphalt concrete in unconfined compression. Transportation Research Record: Journal of the Transportation Research Board. Washington, DC; 2003. p. 3-15. [11] Schwartz CW, Gibson NH, Schapery RA, Witczak MW. Viscoplasticity modeling of asphalt concrete behavior. Recent Advances in Materials Characterization and Modeling of Pavement Systems. New York, NY., United states; 2004.

[12] Schapery RA. Nonlinear viscoelastic and viscoplastic constitutive equations based on thermodynamics. Mechanics of Time-Dependent Materials. 1997;1(2):209-40.

[13] Kim YR, Guddati MN, Underwood BS, Yun T. Development of a multiaxial viscoelastoplastic continuum damage model for asphalt mixtures. McLean, VA: Federal Highway Administration; Project Report FHWA-HRT-08-073; 2009.

[14] Rabotnov YN. Creep problems in structural members. Amsterdam, the Netherlands: North-Holland; 1969.

[15] Kachanov LM. Introduction to continuum damage mechanics. New York, NY: Springer, LLC; 1986.

[16] Lemaitre J, Desmorat R. Engineering damage mechanics: Ductile, creep, fatigue and brittle failures. New York, NY: Springer, LLC; 2005.

[17] Perzyna P. Thermodynamic theory of viscoplastcity. Advances in Applied Mechanics. 1971;11:31354.

[18] Tashman L, Masad E, Zbib H, Little D, Kaloush K. Anisotropic viscoplastic continuum damage model for asphalt mixes. Recent Advances in Materials Characterization and Modeling of Pavement Systems, 15th Engineering Mechanics Division Conference. New York, NY; 2004.

[19] Masad E, Tashman L, Little D, Zbib H. Viscoplastic modeling of asphalt mixes with the effects of anisotropy, damage and aggregate characteristics. Mechanics of Materials. 2005;37(12):1242-56.

[20] Saadeh S, Masad E, Little D. Characterization of asphalt mix response under repeated loading using anisotropic nonlinear viscoelastic-viscoplastic model. Journal of Materials in Civil Engineering. 2007;19(10):912-24.

[21] Abu Al-Rub RK, Darabi MK, Little DN, Masad EA. A micro-damage healing model that improves prediction of fatigue life in asphalt mixes. International Journal of Engineering Science. 2010;48(11):96690.

[22] Darabi MK, Abu Al-Rub RK, Masad EA, Huang C-W, Little DN. A thermo-viscoelasticviscoplastic-viscodamage constitutive model for asphaltic materials. International Journal of Solids and Structures. 2011;48(1):191-207.

[23] Abu Al-Rub RK, Darabi MK. A thermodynamic framework for constitutive modeling of time- and rate-dependent materials. Part i: Theory. International Journal of Plasticity. 2012;34(0):61-92.

[24] Zhou F, Scullion T. Discussion: Three stages of permanent deformation curve and rutting model. International Journal of Pavement Engineering. 2002;3(4):251-60.

[25] Ramsamooj DV, Ramadan J. Prediction of permanent deformation of asphalt concrete in cyclic and monotonic loading. J Test Eval. 1999;27(5):320-6.

[26] Lytton RL. Characterizing asphalt pavements for performance. Transportation Research Record: Journal of the Transportation Research Board. Washington, DC.; 2000. p. 5-16.

[27] Wang LB, Myers LA, Mohammad LN, Fu YR. Micromechanics study on top-down cracking.

Transportation Research Record: Journal of the Transportation Research Board. Washington, D.C.; 2003. p. 121-33.

[28] Freitas EF, Pereira P, Picado-Santos L, Papagiannakis AT. Effect of construction quality, temperature, and rutting on initiation of top-down cracking. Transportation Research Record: Journal of the Transportation Research Board. Washington, D.C.; 2005. p. 174-82.

[29] Underwood B, Yun T, Kim Y. Experimental investigations of the viscoelastic and damage behaviors of hot-mix asphalt in compression. Journal of Materials in Civil Engineering. 2011;23(4):459-66.

[30] Zhang Y, Luo R, Lytton RL. Mechanistic modeling of fracture in asphalt mixtures under compressive loading. Journal of Materials in Civil Engineering. 2013;25(9):1189-97. 
[31] Zhang Y, Luo R, Lytton RL. Characterizing permanent deformation and fracture of asphalt mixtures by using compressive dynamic modulus tests. Journal of Materials in Civil Engineering. 2012;24(7):898906.

[32] Zhang Y, Luo R, Lytton RL. Anisotropic characterization of crack growth in tertiary flow of asphalt mixtures in compression. Journal of Engineering Mechanics. 2014;140(6):in press.

[33] Jones RD. Shrp materials reference library: Asphalt cements: A concise data compilation. National

Research Council, Washington, DC: Strategic Highway Research Program, SHRP-A-645; 1993.

[34] TxDOT. Standard specifications for construction and maintenance of highways, streets, and bridges.

Austin, TX: Texas Department of Transportation; 2004.

[35] TxDOT. Test procedure for design of bituminous mixtures. TxDOT Designation: Tex-204-F. Austin, TX: Texas Department of Transportation; 2008.

[36] Zhang Y, Luo R, Lytton RL. Characterization of viscoplastic yielding of asphalt concrete.

Construction and Building Materials. 2013;47(10):671-9.

[37] Si Z, Little DN, Lytton RL. Characterization of microdamage and healing of asphalt concrete mixtures. Journal of Materials in Civil Engineering. 2002;14(6):461-70.

[38] Hoek E, Bieniawski ZT. Brittle fracture propagation in rock under compression. International Journal of Fracture Mechanics. 1965;1(3):137-55.

[39] Germanovich LN, Salganik RL, Dyskin AV, Lee KK. Mechanisms of brittle fracture of rock with pre-existing cracks in compression. PAGEOPH. 1994;143(1-3):117-49.

[40] Reyes O, Einstein HH. Failure mechanisms of fractured rock - a fracture coalescence model. 7th ISRM Congress. Aachen, Germany; 1991. p. 333-40.

[41] Dyskin AV, Sahouryeh E, Jewell RJ, Joer H, Ustinov KB. Influence of shape and locations of initial 3 -d cracks on their growth in uniaxial compression. Engineering Fracture Mechanics. 2003;70(15):211536.

[42] Perez N. Fracture mechanics. Boston, MA: Kluwer Academic Publishers; 2004.

[43] Dugdale DS. Yielding of steel sheets containing slits. Jourml of the Mechanics andphysics of Solids. 1960;8:100-4.

[44] Gdoutos EE. Fracture mechanics an introduction. Second ed. Norwell, MA: Springer; 2005.

[45] Luo R, Lytton R. Determination of crack size distribution in asphalt mixtures. Transportation

Research Record: Journal of the Transportation Research Board. Washington, DC; 2011. p. 113-21.

[46] Shashidhar N. X-ray tomography of asphalt concrete. Transportation Research Record: Journal of the Transportation Research Board. Washington, DC; 1999. p. 186-92.

[47] Wang L, Frost J, Shashidhar N. Microstructure study of westrack mixes from X-ray tomography images. Transportation Research Record: Journal of the Transportation Research Board. Washington DC; 2001. p. 85-94.

[48] Masad E, Jandhyala V, Dasgupta N, Somadevan N, Shashidhar N. Characterization of air void distribution in asphalt mixes using $\mathrm{x}$-ray computed tomography. Journal of Materials in Civil Engineering. 2002;14(2):122-9.

[49] Arambula E, Masad E, Martin A. Influence of air void distribution on the moisture susceptibility of asphalt mixes. Journal of Materials in Civil Engineering. 2007;19(8):655-64.

[50] Kassem E, Masad E, Lytton R, Bulut R. Measurements of the moisture diffusion coefficient of asphalt mixtures and its relationship to mixture composition. International Journal of Pavement Engineering. 2009;10(6):389-99.

[51] Kassem E, Walubita L, Scullion T, Masad E, Wimsatt A. Evaluation of full-depth asphalt pavement construction using $\mathrm{x}$-ray computed tomography and ground penetrating radar. Journal of Performance of Constructed Facilities. 2008;22(6):408-16.

[52] Cheng D, Little D, Lytton R, Holste J. Surface energy measurement of asphalt and its application to predicting fatigue and healing in asphalt mixtures. Transportation Research Record: Journal of the Transportation Research Board. 2002;1810(1):44-53.

[53] Lytton RL, Masad EA, Zollinger C, Bulut R, Little D. Measurements of surface energy and its relationship to moisture damage. College Station, Texas: Texas Transportation Institute; Report No. FHWA/TX-05/0-4524-2; 2005. 
[54] Little DN, Bhasin A. Using surface energy measurements to select materials for asphalt pavement. Washington, DC: Transportation Research Board, National Research Council; National Cooperative Highway Research Program (NCHRP), Report 104; 2006.

[55] Bhasin A, Little D. Characterization of aggregate surface energy using the universal sorption device. Journal of Materials in Civil Engineering. 2007;19(8):634-41.

[56] Tong Y, Luo R, Lytton R. Modeling water vapor diffusion in pavement and its influence on fatigue crack growth of fine aggregate mixture. Transportation Research Record: Journal of the Transportation Research Board. 2013;2373(1):71-80.

[57] Onyango MA, Romanoschi SA. Verification of mechanistic prediction models for asphalt mixes. Pavement Materials, Structures, and Performance, Geo-Shanghai. Shanghai, China; 2014. 


\section{List of Figures}

Fig. 1. Stress-pseudostrain curve of an asphalt concrete and calculations of dissipated pseudostrain energy (DPSE) and recoverable pseudostrain energy (RPSE).

Fig. 2. Localized tensile principal stresses of a rock-like specimen with two pre-existing inclined cracks subject to external compressive stresses in vertical direction [40].

Fig. 3. Image and schematic plots of three dimensional wing cracks in a transparent resin sample induced by external compressive loads in vertical direction [41].

Fig. 4. Configurations of a pre-existing crack and propagated wing cracks under an external compressive load in vertical direction.

Fig.5. Relationship between average air void radius and air void content of asphalt mixtures including both laboratory and field samples.

Fig. 6. Bond energy of asphalt mixtures determined using crack initiation criterion.

Fig. 7. Critical energy ratio for different asphalt mixtures at different conditions.

Fig. 8. Bond energy of six different asphalt mixtures at various loading rates determined based on the uniaxial compressive strength test data.

Fig. 9. Comparison between predicted compressive strength using simplified crack initiation criterion and the measured compressive strength at different confining pressures. 